
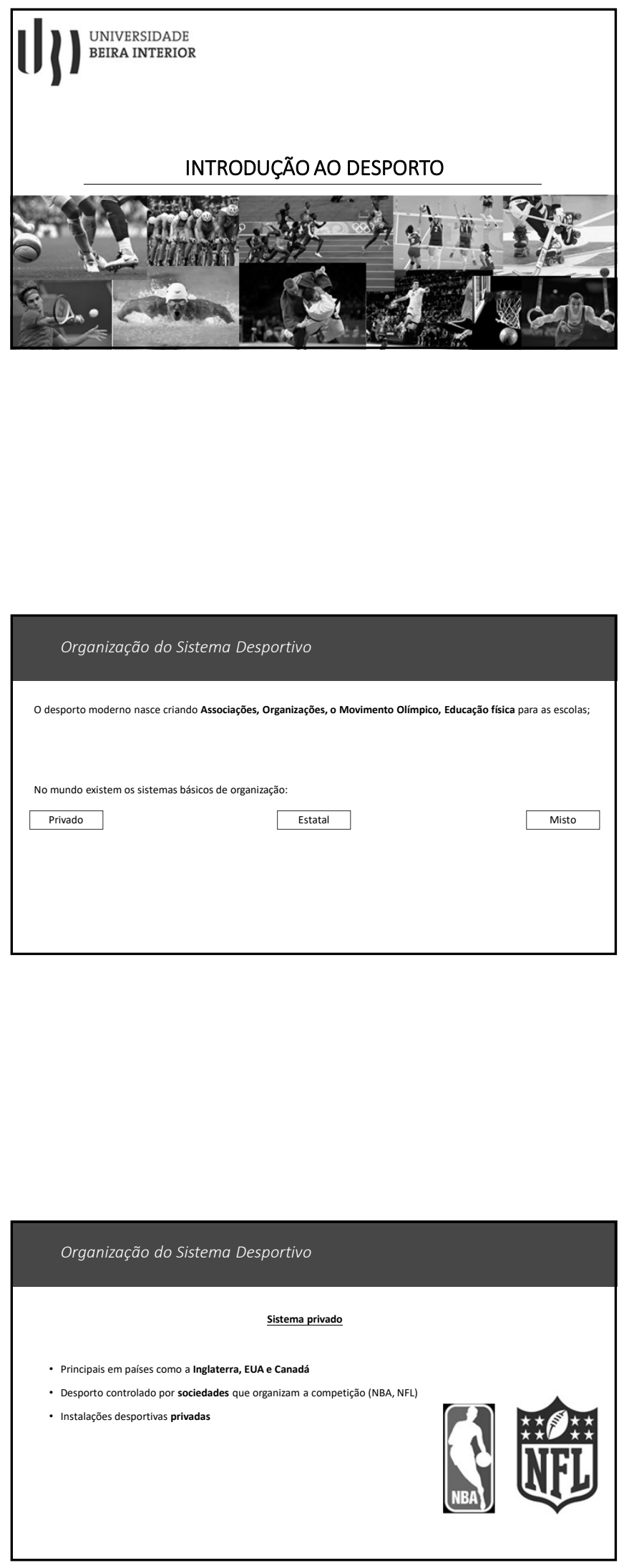
- O estado patrocina tudo

- Por vezes são da polícia, exército ou sindicatos

- Instalaçōes desportivas públicas

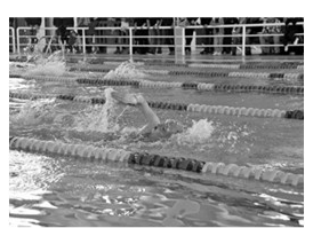

Organização do Sistema Desportivo

\section{O sistema misto}

- Fortes subvençōes do estado às Federaçōes, Associaçōes, Clubes

- Instalações desportivas públicas e privadas

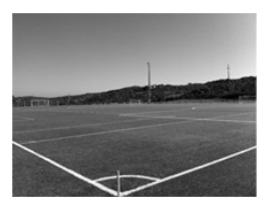

Sistema Desportivo - Enquadramento Europeu

Carta Europeia do Desporto (Maio de 1992)

Os Governos dos diversos países, tendo em conta a promoção do desporto como fator do desenvolvimento humano, tomaram um conjunto de medidas que vão ao encontro das disposiç̃es da Carta Europeia de Desporto e estão en conformidade com os princípios enunciados no Código da Ética do Desporto 

aplicąăoo das disposiç̄eses da presente Carta, de acordo com os princípios enunciados no Código da Ética do Desporto, a fim de:

1. Dar a cada individuo a possibilidade de praticar desporto, nomeadamente:

a) Assegurando a todosos os jovens a possibilidade de beneficiar de programas de educaçăofisica para desenvolver ras suas aptidöes desportivas de base; b) Assegurando a cada um a possibilidade de praticar desporto e de participar em atvidades fisicas e recreativas num ambiente seguro e saudivel; e en cooperaçăo com os organismos desportivos apropriados.

ch Asegride potencial de desenvolvimento pessoal e/ou de alcancar niveis de excelência publicamente reconhecidos.

1. Proteger e desenvolver as bases morais e éticas do desporto, assim como a dignidade humana e a segurança daqueles que participam atividades desportivas, protegendo o desporto e os desportistas de toda a exploraçăo para fins politicos, comerciais e financeiros, e de prática abusivas e aviltantes, incluindo o abuso de drogas.

\section{Sistema Desportivo - Enquadramento Europeu}

- Entende-se por "desporto" todas as formas de atividades físicas que, através de uma participação organizada ou não, têm por objetivo a expressão ou a melhoria da condição física e psiquica, o desenvolvimento das relações sociais ou a obtenção de resultados na competiç̃o a todos os nivets

\section{PESQUISA 1.}

1. Escolhe uma modalidade desportiva

2. Pesquisa a entidade mundial que a regula, $e$ a entidade europeia;

3. Pesquisa o site de 10 Organizações Nacionais (Federações, Associaçōes, Clubes, etc)

Aponta os teus resultados. 
- União europeia (https://europa.eu/european-union/topics/sport_pt)

- Comité Olimpico Internacional (https://www.olympic.org/)

- FIFA (http://www.fifa.com/)

- International Council of Sport Science and Physical Education (https://www.icsspe.org/)

- Organização Mundial de Saúde (http://www.euro.who.int/en/home)
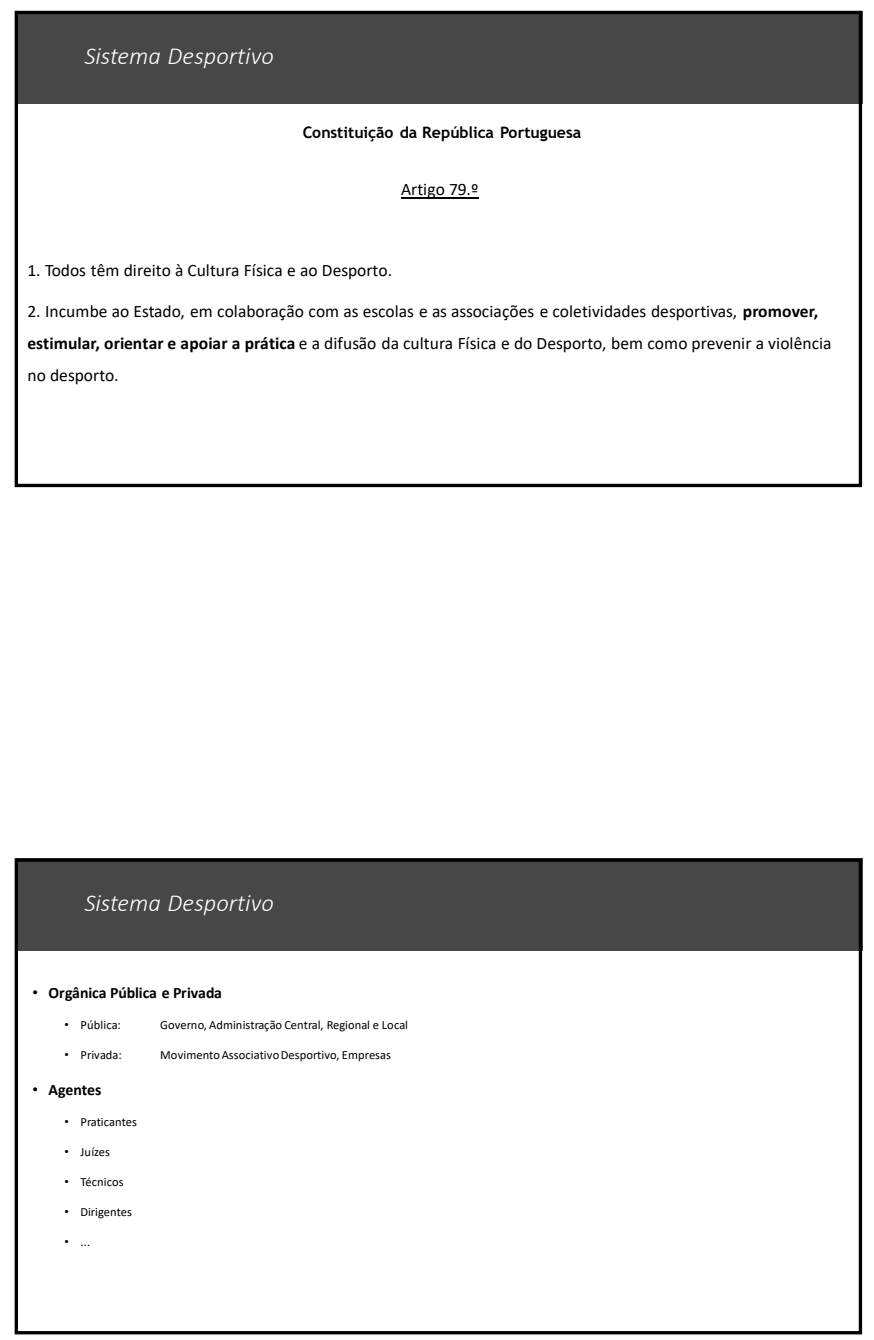

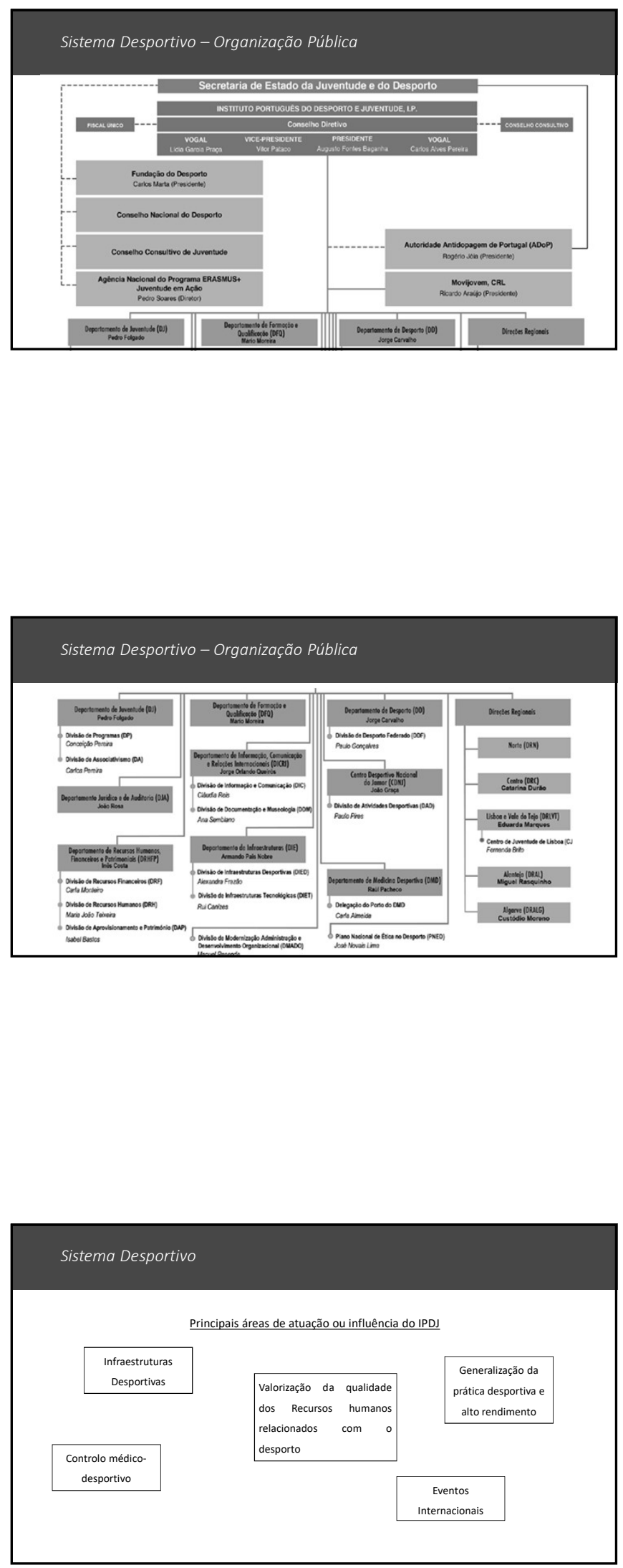
Movimento Associativo Desportivo

\section{CDP $\leftarrow$ Federações desportivas \\ CDP
COP Federaçōes \\ Associaçoes Regionais ou de Base Territorial}

Clubes Desportivos

Clubes de praticantes

Associações Promotoras de Desporto

\section{Sistema Desportivo - Sistema Intervencionista}

Público

- Governo;

- Conselho Nacional do Desporto (órgăo consultivo)

- Instituto Português do Desporto e Juventude (Adm Central)

- Instituto do Desporto Região Autónoma da Madeira (Adm Reg.)

- Direção Regional Desporto (Adm Reg.)

- Câmaras Municipais (Adm Local)

\section{Privado/ Associativo}

- Comité Olímpico de Portugal

- Confederaçăo do Desporto de Portugal

- Federaç̄ös Desportivas

- Associaçäes da Modalidade

- Clubes

- sAD's

- Ligas Profissionais;

- Associaçöes de Treinadores e outras

- Fundaçăo do Desporto

\section{Sistema Desportivo - Sistema Intervencionista}

Desde a década de 40, Portugal, a par da Espanha, da Itália, da França e da Grécia, independentemente das opç̃es e alterações políticas, é um país onde não há Desporto sem a presença dos poderes públicos.

Uma das valências desta intervenção pública na organização e desenvolvimento da prática desportiva traduz-se na produção legislativa.

É claro para todos que a legislação é um fator de desenvolvimento desportivo e como tal desempenha um papel fundamental na construç̃o do sistema desportivo. 


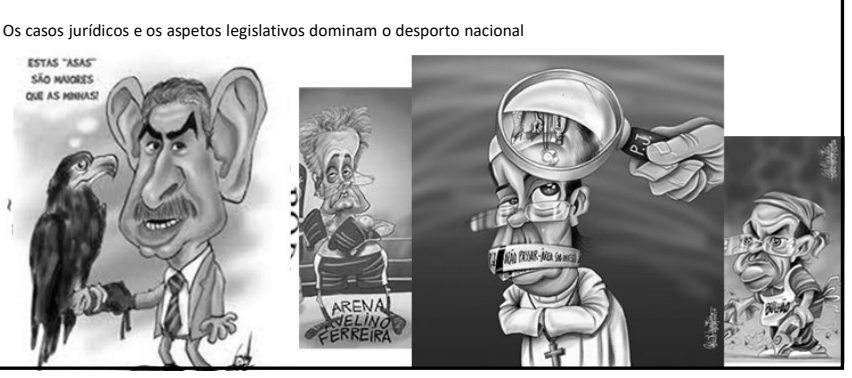

\section{Sistema Desportivo - Sistema Intervencionista}

\section{PESQUISA 2.}

1. Pesquisa por "Lei de Bases da Atividade Física e do Desporto"

2. Pesquisa por "A Carta Europeia do Desporto - Conselho da Europa".

3. Pesquisa por "Modelo Europeu de Organização do Desporto"

Pretende-se conhecer os objetivos de cada um.

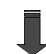

$\checkmark$ Anteprojecto sobre os Princípios Gerais do Sistema Desportivo;

$\checkmark$ Proposta alternativa da Federação Portuguesa de Futebol;

$\checkmark$ Proposta alternativa do Comité Olimpico Português;

$\checkmark$ Projecto de lei n.o 336/V (Lei Quadro da Cultura Física e do Desporto - PCP);

$\checkmark$ Proposta de lei n.o 82/V (Lei de Bases do Sistema Desportivo). 


\section{Antecedentes legislativos}

- A Lei n.o 1/90, de 13 de Janeiro (Lei de Bases do Sistema Desportivo) vigorou durante 14 anos, tendo sido sujeita a uma alteração em 1996

- Em 2004 o Governo faz aprovar a Lei de Bases do Desporto. A Lei n.. 30/2004, de 21 de Julho não suscito regulamentação de qualquer matéria nela consignado.

Lei de Bases do Desporto Lei no 30/2004, de 21 de Julho

Lei da Actividade Física e do Desporto

Lei n.. 5/2007, de 16 de Janeiro
Sistema intervencionista

- 17 anos de vigência de uma lei de enquadramento, definidora dos principios gerais do sistema desportivo
LEI N.9 5/2007, de 16 de Janeiro

OBJECTO E PRINCÍPIOS GERAIS

POLÍTICAS PÚBLICAS

(artigos 6.? a 11.

LBSD
5 Cap. Capitulo III

ASSOCIATIVISMO DESPORTIVO

(artigos 12..9 27.9)

Capitulo IV

ACTIVIDADE FÍSICA E DESPORTIVA

(artigos 28.. a 44..9)

Capitulo

EISCALIDADE

(artigos 45. ㅇ a 4 .9.

DISPOSIÇÕES FINAIS

DISPOSIÇÕES FIN
LBD
13 Cap.
C .

90 art.s

\section{Lei de Bases da Atividade Física e do Desporto}

$$
\text { Capitulo I }
$$

$\checkmark$ Objeto e Princípios Gerais

Artigo 2.o - Princípios da universalidade e da igualdade

Artigo 3.ㅇ - Princípio da ética desportiva

Artigo 4.․ - Princípio da coesão e da continuidade territorial

Artigo 5.o - Princípios da coordenação, da descentralização e da colaboraç̃ão 


\begin{tabular}{|l|}
\hline Ausência: \\
-Principios do reconhecimento e da relevância do associativismo desportivo \\
e das suas organizações.
\end{tabular}

Lei de Bases da Atividade Física e do Desporto

iticas Públicas

Promoção da atividade física

Sstado em estrita articulação com as REGIÕES AUTÓNOMAS e autarquias locais devem criar programas que visem:

Criar espaços públicos:

$>$ Incentivar a integração da at. fisica nos hábitos de vida;

$>$ Promover a conciliação das diferentes facetas da vida.

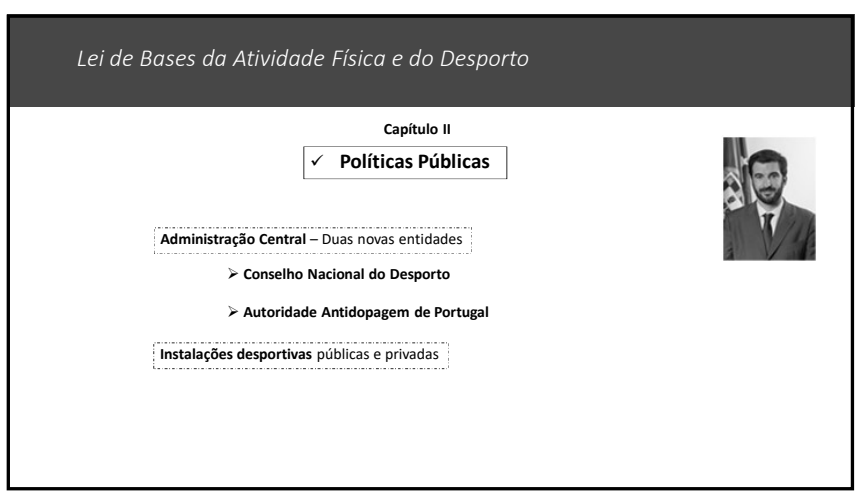




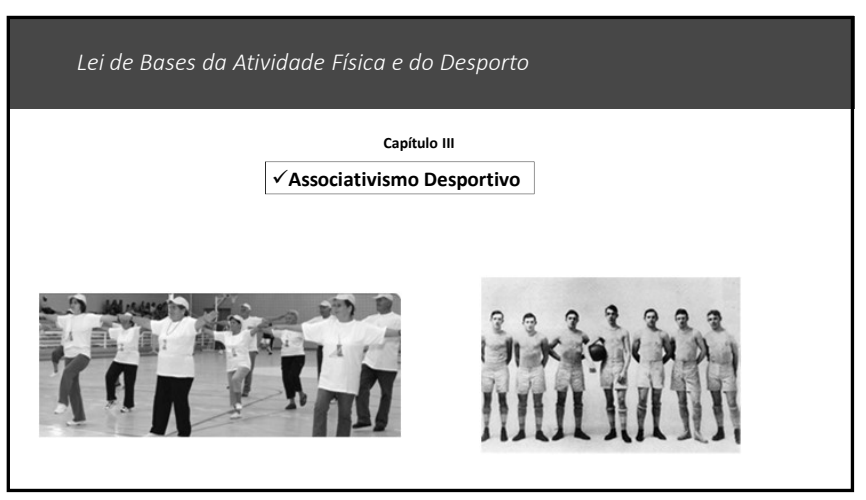

Lei de Bases da Atividade Física e do Desporto

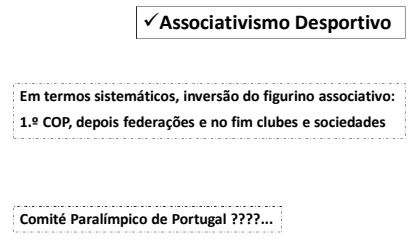

Comité Paralímpico de Portugal ????... 


\section{$\checkmark$ Associativismo Desportivo}

\section{Federaçōes Desportivas}

Deliberações sociais - ingerência abusiva.

> Proibição dos votos de representação nas assembleias-gerais das federações desportivas, ligas profissionais e associaçōes de âmbito territorial.

D Imposição do escrutínio secreto para a tomada de deliberaçōes respeitantes aos titulares dos órgãos, ou à apreciação de comportamentos ou qualidades de qualquer pessoa.

\section{Lei de Bases da Atividade Física e do Desporto}

\section{$\checkmark$ Associativismo Desportivo}

Liga profissional

$>$ Associação sem fins lucrativos

$>$ Integra os clubes e sociedades desportivas e pode integrar representantes de outros agentes desportivos, nomeadamente dos praticantes e dos treinadores:

D Elabora e aprova os regulamentos de arbitragem e disciplina que serão ratificados pela assembleia-geral da federaçăa

\section{Lei de Bases da Atividade Física e do Desporto}

\section{$\checkmark$ Associativismo Desportivo}

Relação entre Federação e Liga

$>$ O relacionamento entre a Federação e a Liga é estabelecido por contrato;

$>$ Na falta de acordo na celebração ou renovação deste contrato, o Conselho Nacional do Desporto regula determinadas matérias > Unicidade orgânica dos conselhos de arbitragem e de disciplina nas federaçōes desportivas, organizados em secç̄ōes que os avalia. 


\section{$\checkmark$ Associativismo Desportivo}

\section{Clubes e Sociedades Desportivas}

> Clubes desportivos: associação sem fins lucrativos tradicional e associação sujeita ao regime especial de gestão (comp. profissional):

> Sociedades desportivas tanto para competiçōes profissionais como para não profissionais.

Ausência: dos clubes de praticantes e deslocação das associaçōes promotoras de desporto (capitulo IV)

\section{$\checkmark$ Actividade Física e Desportiva}

Desporto nos estabelecimentos de ensino

$>$ Prática desportiva por pessoas portadoras de deficiência;

> Jogos tradicionais;

$>$ Desporto na natureza;

> Provas ou manifestaçōes desportivas em locais públicos

> Associaçōes promotoras de desporto:

$>$ Agentes desportivo

† Praticantes desportivos; Formaçăo de técnicos; Titulares de cargos dirigentes desportivos; Empresário desportivos; Apoio ao voluntariado

\section{Lei de Bases da Atividade Física e do Desporto}

\section{Capítulo IV}

$\checkmark$ Actividade Física e Desportiva

$>$ Proteção dos agentes desportivos

* Medicina desportiva

† Segurança social

\% Seguros

Obrigaç̃es das entidades prestadoras de serviços desportivo

$>$ Alto rendimento

* Medidas de apoio

+ Seleções nacionais 
Lei de Bases da Atividade Física e do Desporto

Capitulo $v$

$\checkmark$ Financiamento Público ao Desporto

Apoios financeiros

- Apenas às associaçöes detentoras do estatuto de utilidade pública

- Proibição de apoiar financeiramente os clubes desportivos participantes em competições desportivas profissionais, sob qualquer forma, salvo para a construçăo ou melhoramento de infraestruturas com vista à realização de

competiçōes de interesse público.

(E AS SOCIEDADES DESPORTIVAS ??)
Lei de Bases da Atividade Física e do Desporto

\section{$\checkmark$ Financiamento Público ao Desporto}

Regimes fiscais

$>0$ regime fiscal dos praticantes desportivos - profissōes de desgaste rápido;

$>$ As bolsas para os atletas de alto rendimento têm um regime fiscal estabelecido na lei;

$>$ Estatuto do Mecenato - relevância fiscal para os donativos em dinheiro ou em espécie.
Lei de Bases da Atividade Física e do Desporto

Capitulo VI

$\checkmark$ Disposições finais

$>$ Acesso a espetáculos desportivos;

$>$ Situaçōes especiais:

$>$ Regulamentação;

$>$ Norma revogatória. 
- Regime Jurídico das Federações Desportivas

- Regime Disciplinar das Federações Desportivas

- Regime Jurídico da Formação Desportiva

- Regime Jurídico do combate à violência, ao racismo, à xenofobia e à intolerância nos Espetáculos Desportivos

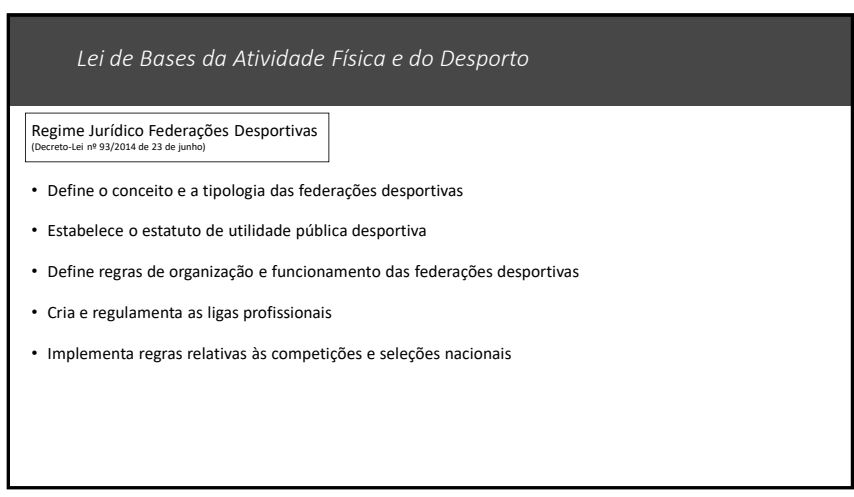


Regime Disciplinar das Federações

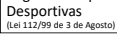

- Apresenta um quadro sancionatório adequado à defesa da ética desportiva e também um

conjunto de ações que visam a obtenção de resultados de boas práticas integradas no fenómeno

desportivo;

- Estabelece o quadro de inibições e suspensão da atividade desportiva para além de prever o

regime de incompatibilidades e impedimentos.

\section{Lei de Bases da Atividade Física e do Desporto}

\section{Regime Jurídico da Formaç̧̃o Desportiva}

- Define:

• Formaçăo profissional desportiva

- Entidade certificadora

- Entidade formadora

- Perfil profissional

- Perfil de formação

- Recursos humanos

\section{Lei de Bases da Atividade Física e do Desporto}

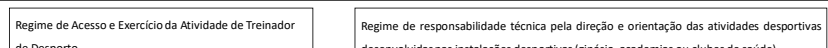
de Desporto

(tete $40 / 2012$ de 28 de agesto)

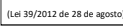

- Define:

- As condiçöes de acesso ao titulo profisisional de treinador de desport

- O regime sancionatório do exerćcici ilegal da atividade de treinad

Condiç̄es de acesso ao titulo de diretor técnico e de técnico de exerciciciofisico

- Regime sancionatório do exerćcicio destas atividades

- Funcionamento das instalaç̋̈es desportivas 
-http://www.ipdj.pt/

\begin{tabular}{|l|}
\hline \\
PESQuisA 3. \\
1. Como posso ter acesso ao titulo profissional de técnico de exercicicio fisico (requisitios) \\
2. Qual a validade? \\
3. O que é necessário para revalidar otitullo? \\
4. O que såo Unidades de Crédito? \\
5. Como podemos obter Unidades de Crédito? \\
\hline
\end{tabular}

\begin{tabular}{|c|}
\hline Cédula de Treinador \\
\hline 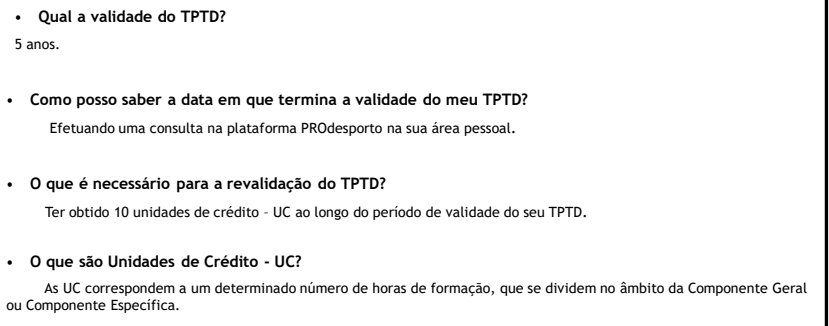 \\
\hline
\end{tabular}


- Como se obtêm Unidades de Crédito UC

As UC podem ser obtidas nos seguintes contextos:

"Açōes de Formação Continua, certificadas pelo IPDJ:

- Presenciais $-1 \mathrm{UC}=5 \mathrm{~h}$

À distância $-1 \mathrm{UC}=10$

\section{"Conclusão de Formação Académica:}

Na área do Desporto ou Ed. Fisica = 5 UC na componente geral (acresce 5 UC na componente especifica caso a formaçăo zação em Esgrima)

Em funçōes de Formador em açōes certificadas (Cursos de Treinador ou Formaçăo Continua) - Não podendo por esta via

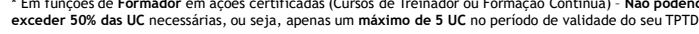

- Formador - número de horas correspondentes a a lectionado, com indicacáo de componente geral ou componente especifica

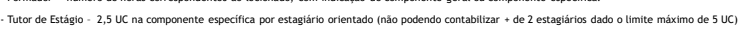

\section{Cédula de Treinador}

- Formações no estrangeiro:

Sujeitas a validação "caso a caso" pelo IPDJ (seguir metodologia especificada no site IPDJ)

- Posso revalidar o meu TPTD com 10 UC de qualquer natureza?

Não.

- Das 10 UC necessárias, apenas 5 UC podem ser obtidas em formação à distância.

- O número máximo de UC da Componente Geral e Componente Especifica também varia em funçāo do Grau de Treinador em causa:

- Treinadores de Grau l e II têm obrigatoriamente de ter 5 UC obtidas na Componente Especifica.

- Treinadores de Grau III podem ter as $10 \mathrm{UC}$ na Componente Geral e/ou Especifica.

- Posso fazer transitar para o período seguinte de validade do meu TPTD algumas UC em excesso? 